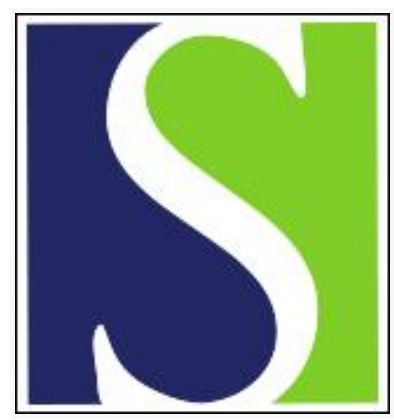

Scand J Work Environ Health 2006;32(2):132-138

https://doi.org/10.5271/sjweh.988

Issue date: 30 Apr 2006

Adolescents' jobs and the course of dermatitis symptoms throughout puberty

by Radon K, Riu E, Dressel H, Windstetter D, Weinmayr G, Weiland S, Vogelberg C, Scharrer EM, Leupold W, von Mutius E, Nowak D

Affiliation: Unit for Occupational and Environmental Epidemiology \& Net Teaching, Institute for Occupational and Environmental Medicine, Ludwig-Maximilians-University, Ziemssenstrasse 1, D-80336 Munich, Germany. Katja.Radon@med.uni-muenchen.de

Refers to the following text of the Journal: 2002;28(5):328-332

Key terms: adolescent; atopic dermatitis; cohort study; contact dermatitis; contact urticaria; International Study of Asthma and Allergies in Childhood; occupational allergy risk; occupational medicine; puberty

This article in PubMed: www.ncbi.nlm.nih.gov/pubmed/16680383 


\title{
Adolescents' jobs and the course of dermatitis symptoms throughout puberty
}

\author{
by Katja Radon, PhD, ${ }^{1}$ Elena Riu, MD, ${ }^{1,2}$ Holger Dressel, MD, ${ }^{1,3}$ Doris Windstetter, MD, ${ }^{1,4}$ Gudrun Wein- \\ mayr, PhD, ${ }^{3}$ Stephan Weiland, PhD, ${ }^{3}$ Christian Vogelberg, MD, ${ }^{5}$ Eva Maria Scharrer, MD, ${ }^{1,6}$ Wolfgang \\ Leupold, PhD, ${ }^{5}$ Erika von Mutius, PhD, ${ }^{4}$ Dennis Nowak, PhD, ${ }^{1}$
}

\begin{abstract}
Radon K, Riu E, Dressel H, Windstetter D, Weinmayr G, Weiland S, Vogelberg C, Scharrer EM, Leupold W, von Mutius E, Nowak D. Adolescents' jobs and the course of dermatitis symptoms throughout puberty. Scand J Work Environ Health 2006;32(2):132-137.
\end{abstract}

\begin{abstract}
Objectives This study evaluated the course of dermatitis symptoms throughout puberty taking into account occupational exposures in a population-based study.

Methods Participants enrolled in the ISAAC-II (International Study of Asthma and Allergies in Childhood) study in Munich and Dresden in 1995 and 1996 were sent a postal questionnaire in 2002 (age at follow-up 16 to 18 years). The questionnaire included items on atopic diseases, jobs, including holiday jobs and vocational training, and potential confounders. The most recent of the adolescents' jobs held for at least 8 hours a week, and for at least 1 month, were coded according to the ISCO-88 system.

Results Overall, data of 3785 adolescents were included in the analyses. The incidence of dermatitis symptoms during puberty among those without such symptoms at baseline was $7 \%$. Altogether $31 \%$ of the participants reported an employment history. Those already employed were more likely to report a new onset of dermatitis symptoms. Jobs associated with a new onset of symptoms were work in the health care sector, vocational training in bakeries, and cleaning. The first 9 months of exposure were particularly relevant for new cases of dermatitis symptoms (odds ratio 3.7, 95\% confidence interval 1.5-9.6).
\end{abstract}

Conclusions Early occupational exposure is associated with the development of symptoms of dermatitis. The types of skin alterations need to be assessed in the next stage of the study.

Key terms adolescents; atopic dermatitis; cohort study; contact dermatitis; contact urticaria; International Study of Asthma and Allergies in Childhood; occupational medicine; study on occupational allergy risks.

Skin diseases caused or aggravated by occupational factors account for a large number of work-related diseases $(1,2)$. Occupational skin diseases mainly affect young women at the beginning of their professional life $(1,3-7)$, and the prognosis is often poor (8). They have considerable social, as well as economic, implications for the individual worker, as well as for society in terms of treatment, compensation, and retraining (9). For Germany, it has been estimated that, in about two-thirds of cases of occupational skin diseases, irritant contact dermatitis can be found, and, in about one-third, type IV allergies contribute to the disease, while $19 \%$ is associated with atopic dermatitis (10). The contact urticaria syndrome is less frequently associated with occupational exposures (2). Wet work is one important risk factor in the development of occupational skin diseases, especially hand dermatitis $(1,4,5,11)$. The main occupations affected are hairdressers, beauticians, bakers, cooks, cleaners, nurses, food processors, and mechanics $(1,3$, 10).

Most of the data on occupational skin disease come from register-based studies and surveillance schemes (1,

1 Institute for Occupational and Environmental Medicine, Munich, Germany.

2 Hospital Germans I Pujol, Badalona, Spain.

3 Department of Epidemiology, Ulm, Germany.

4 Dr von Haunersches Children's Hospital Munich, Germany.

5 University Children's Hospital, Dresden, Germany.

6 Department of Dermatology and Allergology LMU, Munich, Germany.

Correspondence to: Dr Katja Radon, Unit for Occupational and Environmental Epidemiology \& Net Teaching, Institute for Occupational and Environmental Medicine, Ludwig-Maximilians-University, Ziemssenstrasse 1, D-80336 Munich, Germany. [E-mail: Katja.Radon@med.uni-muenchen.de] 
$3,7,10,12)$, case reports from specialized clinics ( 3 , $13,14)$, and some industry-based cross-sectional (14, $15)$ and cohort studies $(5-7,12,16-21)$. The latter studies have indicated that even short exposure periods may contribute to the development of skin diseases $(1,3-7)$. Such industry-based studies provide valuable information on the incidence and time course of eczema in one specific industry but cannot be generalized to the general population. It was therefore concluded that a prospective population-based survey could be helpful in the study of risk factors and the preventive potential for work environments in the development of occupational skin diseases (1).

In Germany, full-time compulsory education ends at the age of 16 years. Thereafter, more than $60 \%$ of teenagers start vocational training. During vocational training, about one-third are mainly trained at school, while the rest are predominantly trained on the job and attend school for up to 2 days a week only (eg, nurses, electricians, mechanics, secretaries, etc) (22). In addition, it has been estimated that about $25 \%$ of all high school students in Germany have holiday jobs. Therefore, occupational exposure starts early and, in many cases, before the completion of training. However, the impact of these short-term employment histories on occupational skin disease has not yet been studied. Within the Study on Occupational Allergy Risks (SOLAR) we therefore aimed to assess the association between holiday jobs and vocational training and the course of symptoms of dermatitis during puberty in a population-based cohort study.

\section{Study population and methods}

\section{Study population}

The study population of SOLAR consisted of the participants of phase II of the International Study of Asthma and Allergies in Childhood (ISAAC) in Munich and Dresden who were enrolled in 1995 and 1996 as described elsewhere (23). Parents of 3354 children aged 9 to 11 years in Munich (response rate 87.5\%) and 3045 children in Dresden (response rate 83.0\%) responded to the questionnaire. Detailed information on atopic diseases, socioeconomic factors, and environmental risk factors was obtained by a standardized questionnaire. Skin prick tests using ubiquitous allergens $(\mathrm{N}=4578$, response rate $61.1 \%$ ) were administered at baseline in parts of the population.

For the follow-up study, all of the participants were traced using population registries in each community. Overall, 4893 persons could be re-located 6 years after the baseline survey (76\%). In 2002, questionnaires with an informed consent form and up to two reminders were mailed to these participants (age 16 to 18 years). Of these, 3785 filled-out the follow-up questionnaire and gave their informed consent to combine the baseline and follow-up data.

The 121 questions of the follow-up questionnaire were taken mainly from the European Community Respiratory Health Survey (ECRHS) (24) and the ISAAC study (25). A database was set up using double entry.

The study was approved by the Ethical Committee of the Bavarian Chamber of Physicians (Number 02071) and the Ethical Committee of the Department of Medicine, Technical University of Dresden (Number EK96072002).

\section{Definition of exposure}

The participants were asked to specify any job held for at least 8 hours a week and at least 1 month. Each of these jobs was double coded in parallel by two welltrained coders according to the ISCO-88 code (26), reevaluated by an expert and grouped into one of 16 categories. These job categories served as the exposure variable. Overall, $75.2 \%$ of those who ever had a job reported one job, $23.3 \%$ indicated two jobs, and only 14 $(1.5 \%)$ specified more than two jobs. Therefore, only the most recent job was considered as the exposure variable in all of the analyses.

To assess the potential association between the duration of exposure and the incidence of symptoms, we categorized the duration of employment into quartiles for those ever employed for at least 8 hours a week and at least 1 month (1st quartile: 1 month, 2 nd quartile: $\geq 1$ to 9 months, 3rd quartile: $\geq 10$ to 15 months, 4th quartile: $\geq 16$ months).

\section{Outcome definition}

Symptoms of dermatitis were defined as an itchy rash coming and going for at least 6 months at any time in the last 12 months. Physician-diagnosed dermatitis was defined as eczema, skin allergy, or atopic dermatitis ever diagnosed by a physician with symptoms of eczema during the last 12 months. For the latter definition, the participants who reported symptoms of dermatitis but who were not diagnosed by a physician were excluded. Incident cases were compared with those who never experienced symptoms of dermatitis.

Altogether $28 \%$ of those reporting a new onset of dermatitis symptoms also reported nickel allergies. In addition, $72 \%$ of those with a new onset of symptoms reported skin symptoms at the elbows, knees, joints of the hands and feet, on the face, or on the neck. The latter definition has been used in the ISAAC study as the definition for atopic dermatitis (27). Sensitivity analyses using these stricter definitions of dermatitis revealed 
similar risk estimates with wider confidence intervals due to the lower number of participants. Therefore, only the results for the less-specific definition of dermatitis are reported.

\section{Statistical methods}

Cross-tabulation was used to visualize the bivariate distributions of categorical predictors for the participants with incident symptoms of dermatitis and those who never had symptoms of dermatitis.

Multiple logistic regression models were used to assess the association between occupational exposure and the incidence of dermatitis symptoms. For these models, the following variables were considered as potential confounders: gender, place of living, status of em-

Table 1. Characteristics of the participants stratified by work experience. $(\lg \mathrm{E}=$ immunoglobulin $\mathrm{E})$

\begin{tabular}{|c|c|c|c|c|}
\hline \multirow[t]{2}{*}{ Characteristic } & \multicolumn{2}{|c|}{$\begin{array}{c}\text { Never had a } \\
\text { job a, b }(N=2528)\end{array}$} & \multicolumn{2}{|c|}{$\begin{array}{l}\text { Ever worked c, d } \\
\qquad(N=964)\end{array}$} \\
\hline & $\mathrm{N}$ & $\%$ & $\mathrm{~N}$ & $\%$ \\
\hline Gender (male) & 1225 & 48.5 & 453 & 47.0 \\
\hline Center (Dresden) & 1213 & 48.0 & $519 e$ & 53.8 \\
\hline Socioeconomic status ${ }^{\dagger}$ (high) & 1448 & 58.2 & $426^{e}$ & 45.5 \\
\hline Current smoker & 740 & 29.5 & $451^{\mathrm{e}}$ & 47.1 \\
\hline Passive smoke exposure & 1516 & 60.5 & $708^{e}$ & 73.8 \\
\hline \multicolumn{5}{|l|}{ Markers of atopy } \\
\hline Parental atopic dermatitis & 446 & 17.9 & 157 & 16.5 \\
\hline Positive prick test (1st survey) & 534 & 25.1 & 202 & 24.3 \\
\hline Specific IgE >0.35 (1st survey) & 709 & 40.3 & 271 & 37.7 \\
\hline $\begin{array}{l}\text { Symptoms of allergic rhinitis } \\
\text { (2nd survey) }{ }^{g}\end{array}$ & 538 & 21.8 & 226 & 24.2 \\
\hline \multicolumn{5}{|l|}{ Symptoms of dermatitis ${ }^{h, i}$} \\
\hline Never & 2003 & 80.8 & 720 & 76.6 \\
\hline In remission & 224 & 9.0 & 88 & 9.4 \\
\hline Persistent & 122 & 4.9 & 57 & 6.1 \\
\hline Incidence & 130 & 5.2 & 75 & 8.0 \\
\hline \multicolumn{5}{|c|}{ 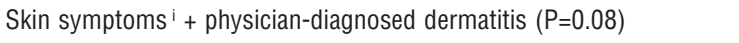 } \\
\hline Never & 1684 & 86.1 & 600 & 83.0 \\
\hline In remission & 139 & 7.1 & 53 & 7.3 \\
\hline Persistent & 105 & 5.4 & 54 & 7.5 \\
\hline Incidence & 27 & 1.4 & 16 & 2.2 \\
\hline \multicolumn{5}{|l|}{ Current state of employment ${ }^{\mathrm{e}}$} \\
\hline Student & 1884 & 74.7 & 532 & 55.4 \\
\hline Vocational trainee or employee & e 585 & 23.2 & 386 & 40.2 \\
\hline Others & 54 & 2.1 & 43 & 4.5 \\
\hline
\end{tabular}

a Ever had a job for $\geq 8$ hours per week for at least 1 month.

b Mean age 16.5 (SD 0.72) years.

c Median duration of employment 10 months (25th-75th quartile 1-16) and median number of weekly workhours 29 (25th-75th quartile 10 40).

d Mean age 16.7 (SD 0.65) years: $P_{t-t e s t}<0.001$ for never had a job versus ever worked.

e $P_{\text {Chi-square }}<0.001$.

f Parental socioeconomic status based on highest level of schooling.

g 12 months' prevalence of eye and nose symptoms at the time of the 2 nd follow-up.

h $\mathrm{P}_{\text {Chi-square }}<0.01$.

i Itchy rash coming and going for at least 6 months at any time over the last 12 months. ployment (student, vocational trainee or employee, other), highest parental level of education $(\leq 11$ years of schooling versus $>11$ years of schooling), parental history of atopy, atopy at first survey (at least one positive skin prick test result), active smoking for at least 1 year, regular exposure to environmental tobacco smoke. Age was not considered a confounder because all of the participants were within a limited age range (16-18 years). All of the final multiple logistic regression models were adjusted for the parameters associated with occupational exposure. Gender and place of living were retained in all of the models. Effect modification was assessed using stratified analyses for gender and atopy.

\section{Results}

\section{Response}

Comparing baseline data of the respondents and nonrespondents of the follow-up questionnaire, we found a slightly higher prevalence of dermatitis symptoms among the respondents (14\% versus $12 \%$, respectively, $\mathrm{P}=0.003$ ). The participants in the follow-up survey were more likely to have parents with atopic diseases (44\% versus $36 \%$, respectively, $\mathrm{P}<0.001)$ and parents with a higher level of schooling (54\% versus $42 \%$, respectively, $\mathrm{P}<0.001)$.

Of the participants without German citizenship, the course of dermatitis symptoms, as well as the jobs, differed significantly from those of the rest of the study population. Due to the fact that this group was too small for stratified analyses $(\mathrm{N}=279)$ and only four of them lived in Dresden, we had to exclude these persons from further analyses.

\section{Descriptive data}

Overall, 964 persons (28\%) had ever had a job for at least 8 hours a week and at least 1 month. Table 1 compares the sociodemographic characteristics of those who had never worked and those who ever worked in jobs for at least 1 month and at least 8 hours a week. The participants who had ever worked were slightly older, more likely to be active smokers or to be exposed to environmental tobacco smoke, more likely to live in Dresden, more often in vocational training, and had parents with a lower level of schooling. In addition, these persons had a statistically significant higher incidence of dermatis symptoms $(8 \%$ versus $5 \%, \mathrm{P}<0.01)$.

\section{Occupational exposures and new onset of symptoms of dermatitis}

The most frequent jobs among the participants who were symptom-free at baseline were clerical work $(\mathrm{N}=151)$, 
shop assistants $(\mathrm{N}=151)$, and jobs in gastronomy (mainly waiters, $\mathrm{N}=98$ ) (table 2). Jobs which were only mentioned by fewer than five persons or were not clearly specified were combined into "other jobs" $(\mathrm{N}=78)$.

After adjustment for potential confounders, nurses [odds ratio (OR) 4.9, 95\% confidence interval (95\% CI) 1.9-12.2] and bakers (OR 10.8, 95\% CI 2.9-40.7) had a significantly increased risk of new onset of dermatitis symptoms during the study period. There was also a tendency for an increased risk among assistants in the health care sector [eg, vocational trainees in private practices of physicians, dentists, trainees in physiotherapy and pharmacies (OR 2.1. 95\% CI 0.8-5.7)] and cleaners (OR 3.0, 95\% CI 1.0-9.4). The same pattern was found for physician-diagnosed dermatitis. However, the confidence intervals were large due to the limited number of persons with a new onset of physiciandiagnosed disease.

As the girls were more likely to report a new onset of dermatitis symptoms and also more likely to work in specific jobs (eg, jobs in health care, child care, and cleaning), we assessed effect modification by stratifying the analyses by gender. However, no statistically significant differences in the risk estimates between the boys and girls were found (data not shown). Stratifying for atopy also did not change the results (data not shown).

\section{Exposure duration and incidence of symptoms of dermatitis}

In order to assess the relevant duration of exposure for the development of symptoms, we assessed the associ- ation between the duration of employment in "high-risk jobs" (nurses, health care assistants, bakers, cleaners) and the incidence of symptoms of dermatitis (figure 1). A significantly increased odds ratio for a new onset of dermatitis symptoms was found for those with 2 to 9 months' duration of employment in high-risk occupations (OR 3.7, 95\% CI 1.5-9.6) and for those with up to 15 months of employment (OR 2.5 95\% CI 1.2-5.2).

\section{Discussion}

Our results indicate that, even after a very short duration of employment, occupational exposures are associated with a new onset of dermatitis symptoms. In this young cohort, work in the health care sector, bakeries, and cleaning was especially associated with an increased odds ratio. According to these results, the first 9 months of employment seem to be crucial.

Our study was done prospectively in a general population sample with in-depth data on childhood exposures and symptoms of dermatitis. While at baseline the parents were asked about symptoms and diseases, the participants themselves answered the follow-up questionnaire. Therefore, we were able to take into account the lifetime history of symptoms of dermatitis in our study. We were able to trace a large proportion of our participants after 6 years. In addition, a high response rate could be obtained in order to minimize selection bias. Nevertheless, children of atopic parents with a higher socioeconomic status and symptoms of dermatitis at baseline were more likely to respond to the follow-up questionnaire. Another limitation of our study

Table 2. Incidence of dermatitis by occupational group and the results of the multiple logistic regression models after adjustment for gender, center, positive skin prick test (1st survey), parental level of schooling, smoking, and exposure to environmental tobacco smoke. (boldface $=$ statistically significant odds ratios, $\cdot$ category not applicable due to small numbers)

\begin{tabular}{|c|c|c|c|c|c|c|c|c|c|c|}
\hline \multirow[t]{2}{*}{ Occupational group } & \multicolumn{5}{|c|}{ Symptoms of dermatitis } & \multicolumn{5}{|c|}{ Doctors' diagnosed dermatitis } \\
\hline & $\begin{array}{l}\text { Size of } \\
\text { group } \\
(\mathrm{N})\end{array}$ & $\begin{array}{l}\text { Number } \\
\text { with } \\
\text { symptoms }\end{array}$ & $\%$ & OR & $95 \% \mathrm{Cl}$ & $\begin{array}{l}\text { Size of } \\
\text { group } \\
\text { (N) }\end{array}$ & $\begin{array}{l}\text { Number } \\
\text { with } \\
\text { symptoms }\end{array}$ & $\%$ & $\mathrm{OR}$ & $95 \% \mathrm{Cl}$ \\
\hline Never had a job & 2130 & 129 & 6.1 & 1 & & 1709 & 26 & 1.5 & 1 & \\
\hline Clerks & 151 & 15 & 9.9 & 1.65 & $0.89-3.06$ & 110 & 3 & 2.7 & 2.07 & $0.60-7.13$ \\
\hline Shop assistant & 151 & 12 & 7.9 & 1.03 & $0.50-2.13$ & 116 & 3 & 2.6 & 2.35 & $0.67-8.24$ \\
\hline Child care & 25 & 1 & 4.0 & 0.58 & $0.08-4.36$ & 21 & - & 0.0 & . & . \\
\hline Waiters, other jobs in gastronomy & 98 & 5 & 5.1 & 0.62 & $0.22-1.73$ & 81 & - & 0.0 & . & . \\
\hline Science technicians & 26 & - & 0.0 & . & . & 24 & - & 0.0 & . & . \\
\hline Health care assistants & 40 & 6 & 15.0 & 2.11 & $0.79-5.65$ & 31 & 3 & 9.7 & 5.65 & $1.19-26.71$ \\
\hline Nurses & 31 & 9 & 29.0 & 4.86 & $1.92-12.20$ & 21 & 3 & 14.3 & 7.83 & $1.59-38.68$ \\
\hline Farmers, florists, animal care & 40 & 4 & 10.0 & 1.61 & $0.55-4.67$ & 30 & - & 0.0 & . & . \\
\hline Hairdressers, beauticians & 6 & 1 & 16.7 & . & . & 5 & - & 0.0 & . & . \\
\hline Construction workers & 35 & 4 & 11.4 & 2.42 & $0.69-8.53$ & 31 & 1 & 3.2 & 5.90 & $0.68-51.50$ \\
\hline Metal workers, mechanics & 52 & 3 & 5.8 & 0.83 & $0.20-3.57$ & 39 & - & 0.0 & . & . \\
\hline Electricians and electronic technicians & 20 & - & 0.0 & . & . & 16 & - & 0.0 & . & . \\
\hline Carpenters & 10 & - & 0.0 & . & . & 9 & - & 0.0 & . & . \\
\hline Bakers & 14 & 4 & 30.8 & 10.80 & $2.87-40.69$ & 9 & - & 0.0 & . & . \\
\hline Cleaners & 22 & 4 & 18.2 & 2.98 & $0.95-9.37$ & 21 & 3 & 14.3 & 11.37 & $2.82-45.92$ \\
\hline Others ${ }^{a}$ & 78 & 8 & 10.3 & 1.58 & $0.65-3.81$ & 54 & 1 & 1.9 & . & . \\
\hline
\end{tabular}

a Others: jobs with $<5$ participants and not clearly specified jobs. 


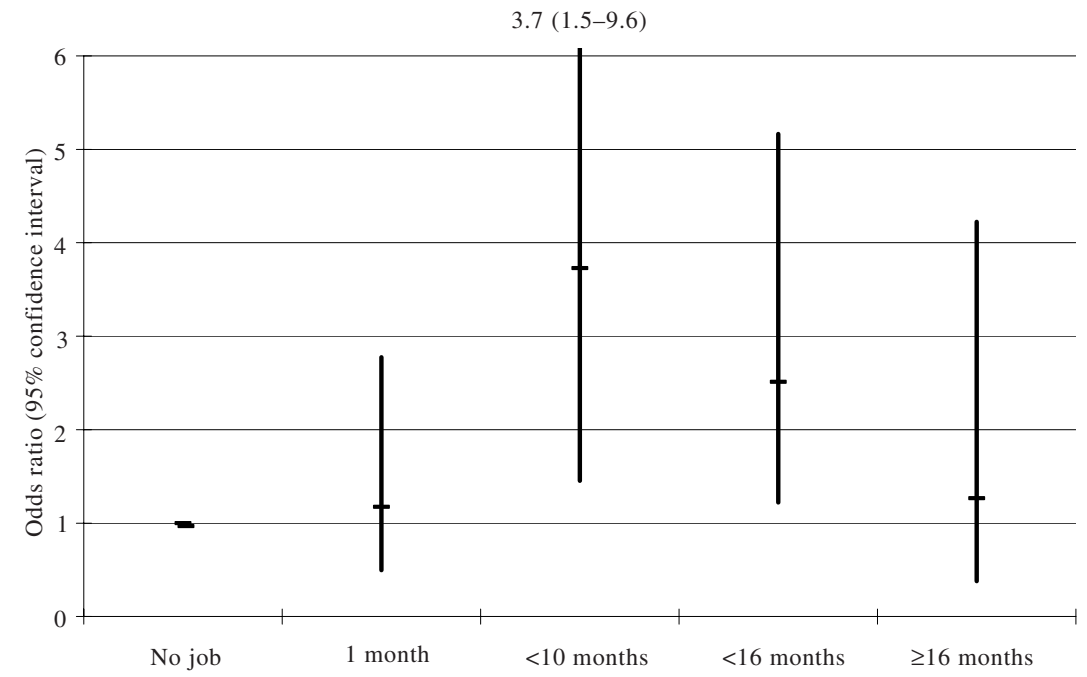

Figure 1. Odds ratios with $95 \%$ confidence intervals for the duration of employment in high-risk jobs (nursing, health care assistance, bakery, or cleaning) by quartiles and the incidence of dermatitis symptoms, adjusted for gender, center, socioeconomic status, smoking, and exposure to environmental tobacco smoke $(\mathrm{N}=2844)$. (Reference category: people who never had a job for at least 8 hours a week for at least a month's duration) was that we could not analyze our data using survival analysis because we did not know the exact onset of the symptoms.

The questionnaire instruments used at baseline and in the follow-up have been thoroughly validated against clinical measurements (27-29). However, due to the fact that we had not done clinical examinations in this follow-up, we were not able to distinguish between atopic dermatitis, irritant or allergic contact eczema, hand eczema, and contact urticaria. Therefore, to discriminate between different forms of eczema better, we will include clinical skin examinations and patch tests in the next follow-up of our study population.

The major drawback of the use of job titles as an exposure surrogate is potential nondifferential misclassification of exposure (30). In order to decrease misclassification, two independent well-trained coders doublecoded the jobs, and the codes were re-evaluated by an expert (30). Furthermore, specificity was chosen over sensitivity. This approach has been shown to reduce misclassification bias when exposure prevalence is low (31).

Particularly the participants working as nurses, health-care assistants, bakers, and cleaners were at an increased risk of incident symptoms of dermatitis. These results confirm recent data from register-based retrospective studies $(3,10,32)$. Exposures relevant at these workplaces do not only include irritants and allergens, but also wet work $(1,33)$.

Even though only about one-third of the population already had an employment history, the decreasing odds ratio for a new onset of symptoms of dermatitis with longer duration of exposure might already indicate a healthy worker selection bias (34). Therefore, this study shows the necessity to start cohort studies at the beginning of occupational life and take holiday jobs and vocational training on the job into account. This approach will enable us to assess the overall impact of occupational exposures in the development of eczema on a population base (1).

Our data indicate that especially the first 9 months of employment in high-risk jobs seem to be important in the development of symptoms of dermatitis. These findings are in accordance with recent results from industry-based cohort studies and register-based studies in which increased incidences of eczema were mainly found in younger age groups (1, 3-7). However, none of these studies was done prospectively in the general population or took into account exposure in holiday jobs. Therefore, it seems that people working only on a shortterm basis in high-risk jobs should be included in routine examinations in order to recognize early signs of occupational disease and to start evidence-based measures of secondary prevention.

In summary, occupational exposure among adolescents is associated with an increased odds ratio of new onsets of symptoms of dermatitis after a short duration of employment in holiday jobs and vocational training. Therefore, measures of primary and secondary prevention in early occupational life are warranted to decrease the risk of occupational skin diseases.

\section{Acknowledgments}

This study was supported by the German Ministry for Economy and Labor. Elena Riu received support in the form of a grant from the European Respiratory Society.

We thank Christian Janßen and Sarah Hümmer for the job coding and the field workers for the field work. Parts of this paper have been used for the medical thesis of Elena Riu. 


\section{References}

1. Meding B. Differences between the sexes with regard to workrelated skin disease. Contact Dermatitis. 2000;43:65-71.

2. Mahler V, Drexler H. Berufsdermatologisch relevante Typ-IAllergen [Dermatologic occupationally relevant type I allergies]. Hautarzt. 2004;55(1):34-41.

3. Dickel H, Kuss O, Blesius CR, Schmidt A, Diepgen TL. Occupational skin diseases in Northern Bavaria between 1990 and 1999: a population-based study. Br J Dermatol. 2001; 145(3):453-62.

4. Wall LM, Gebauer KA. Occupational skin disease in Western Australia. Contact Dermatitis. 1991;24:101-9.

5. Nielsen J. The occurrence and course of skin symptoms on the hands among female cleaners. Contact Dermatitis. 1996; 34:284-91.

6. Uter W, Pfahlberg A, Gefeller O, Schwanitz HJ. Hand dermatitis in a prospectively-followed cohort of hairdressing apprentices: final results of the POSH study. Contact Dermatitis. 1999;41:280-6.

7. Tacke J, Schmidt A, Fartasch M, Diepgen TL. Occupational dermatitis in bakers, confectioners and cooks. Contact Dermatitis. 1995;33:112-7.

8. Jungbauer FHW, van der Vleuten P, Groothoff JW, Coenraads PJ. Irritant hand dermatitis: severity of disease, occupational exposure to skin irritants and preventive measures 5 years after initial diagnosis. Contact Dermatitis. 2004;50:24551.

9. Chew AL, Maibach HI. Occupational issues of irritant contact dermatitis. Int Arch Occup Environ Health. 2003;76(5):33946.

10. Dickel H, Bruckner TM, Bernhard-Klimt C, Koch T, Scheidt R, Diepgen TL. Surveillance scheme for occupational skin disease in the Saarland, FRG. Contact Dermatitis. 2002; 46:197-206.

11. Dickel H, Bruckner TM, Schmidt A, Diepgen TL. Impact of atopic skin diathesis on occupational skin disease incidence in a working population. J Invest Dermatol. 2003;121(1):37-40.

12. Bock M, Schmidt A, Bruckner TM, Diepgen TL. Occupational skin disease in the construction industry. Br J Dermatol. 2003;149:1165-71.

13. Iorizzo M, Parente G, Vincenzi C, Pazzaglia M, Tosti A. Allergic contact dermatitis in hairdressers: frequency and source of sensitisation. Eur J Dermatol. 2002;12:179-82.

14. Holter G, Irgens A, Nyfors A, Aasen TB, Florvaag E, Overa $\mathrm{KB}$, et al. Self-reported skin and respiratory symptoms related to latex exposure among 5087 hospital employees in Norway. Dermatology. 2002;205:28-31.

15. Susitaival P, Kirk J, Schenker MB. Self-reported hand dermatitis in California Veterinarians. Am J Contact Derm. 2001; 12:103-8.

16. Bauer A, Bartsch R, Hersmann C, Stadeler M, Kelterer D, Schneider W, et al. Occupational hand dermatitis in food industry apprentices: results of a 3-year follow-up cohort study. Int Arch Occup Environ Health. 2001;74:437-42.

17. John SM, Uter W, Schwanitz HJ. Relevance of multiparametric skin bioengineering in a prospectively-followed cohort of junior hairdressers. Contact Dermatitis. 2000;43(3):161-8.

18. Holm JO. An epidemiological study of hand eczema. VI. A follow-up of hairdresser trainees, with the focus on various health complaints. Acta Derm Venereol Suppl (Stockh). 1994;187:26-7.

19. Allmers H, Schmengler J, Skudlik C. Primary prevention of natural rubber latex allergy in the German health care system through education and intervention. J Allergy Clin Immunol. 2002;110:318-23.

20. Muller BA. Minimizing latex exposure and allergy. Postgrad Med. 2003;113:91-7.

21. Liss GM, Sussman GL. Latex sensitization: Occupational versus general population prevalence rates. Am J Ind Med. 1999;35:196-200.

22. European Commission. Key data on education in the European Union-2002. Luxembourg: Office for Official Publications of the European Communities; 2002.

23. Weiland SK, von Mutius E, Hirsch T, Duhme H, Fritzsch C, Werner B, et al. Prevalence of respiratory and atopic disorders among children in the East and West of Germany five years after unification. Eur Respir J. 1999;14(4):862-70.

24. Burney P. Ten years of research on asthma in Europe: The European Community Respiratory Health Survey. Rev Epidemiol Sante Publique. 1998;46(6):491-6.

25. Asher MI, Keil U, Anderson HR, Beasley R, Crane J, Martinez F, et al. International Study of Asthma and Allergies in Childhood (ISAAC): rationale and methods. Eur Respir J. 1995;8(3):483-91.

26. International Labour Office (ILO). International standard classification of occupations (ISCO-88). Geneva: ILO Publications; 1991.

27. Williams H, Robertson C, Stewart A, Ait-Khaled N, Anabwani G, Anderson R, et al. Worldwide variations in the prevalence of symptoms of atopic eczema in the International Study of Asthma and Allergies in Childhood. J Allergy Clin Immunol 1999;103(1 Pt 1):125-38.

28. Pearce N, Sunyer J, Cheng S, Chinn S, Bjorksten B, Burr M, et al. Comparison of asthma prevalence in the ISAAC and the ECRHS. Eur Respir J. 2000;16(3):420-6.

29. Renzoni E, Forastiere F, Biggeri A, Viegi G, Bisanti L, Chellini E, et al. Differences in parental- and self-report of asthma, rhinitis and eczema among Italian adolescents: SIDRIA collaborative group. Eur Respir J. 1999;14(3):597-604.

30. Kennedy SM, Le Moual N, Choudat D, Kauffmann F. Development of an asthma specific job exposure matrix and its application in the epidemiological study of genetics and environment in asthma (EGEA). Occup Environ Med. 2000; 57(9):635-1.

31. Kauppinen TP, Mutanen PO, Seitsamo JT. Magnitude of misclassification bias when using a job-exposure matrix. Scand J Work Environ Health. 1992;18(2):105-12.

32. Magina S, Barros MA, Ferreira JA, Mesquita-Guimarae J. Atopy, nickel sensitivity, occupation, and clinical patterns in different types of hand dermatitis. Am J Contact Derm. $2003 ; 14: 63-8$.

33. Jungbauer FHW, Lensen GJ, Groothoff JW, Coenraads PJ. Exposure of the hands to wet work in nurses. Contact Dermatitis. 2004;50:225-9.

34. Radon K, Goldberg M, Becklake M. Healthy worker effect in cohort studies on chronic bronchitis. Scand J Work Environ Health. 2002;28(5):328-32.

Received for publication: 22 July 2005 